\title{
Distribution of Urate Crystal Deposition in the Hands and Wrists of Patients with Chronic Gout
}

\author{
Y Leng', DLY Chow ${ }^{1}$, SK Chui ${ }^{1}$, NSK Ip ${ }^{1}$, SWC Chan $^{1}$, KY Choi ${ }^{2}$, AOC Li $^{1}$ \\ ${ }^{\prime}$ Department of Radiology, Tuen Mun Hospital, Hong Kong \\ ${ }^{2}$ Department of Orthopaedics and Traumatology, Tuen Mun Hospital, Hong Kong
}

\begin{abstract}
Objectives: We sought to examine the frequency and patterns of monosodium urate (MSU) crystal deposition in the hand/wrist in non-acute gout patients using dual-energy computed tomography (DECT).

Methods: All hand/wrist DECT imaging data of patients with chronic tophaceous gout undergoing their first examination before dissolution therapy from March 2015 to March 2019 were identified. Cases without positive MSU crystal deposition were excluded. The reports and images of the positive cases were retrospectively analysed, and the anatomical locations of all urate crystal depositions were recorded.

Results: A total of 48 cases were identified with positive findings. Thirty of the cases had undergone DECT of both hands, and 18 had undergone DECT of a single hand. In total, 60 hands/wrists had flexor tendon involvement. The carpal joints were the most commonly involved site (78.2\%). The carpal tunnel was the most commonly involved soft tissue site in the hand and wrist (71.8\%), followed by the fourth (55.1\%) and fifth (53.8\%) extensor compartments. The second digit extensor digitorum (47.4\%) was the most commonly involved soft tissue site in the hand while the fourth digit flexor digitorum was the most commonly (46.2\%) involved flexor tendon in the hand. In the hand and wrist soft tissue sites, extensor pollicis brevis (11.5\%), flexor carpi ulnaris (11.5\%) and extensor compartment I (11.5\%) were involved least commonly. We found Zones II (75\%) and IV (78.3\%) to be the most commonly involved flexor tendon zones in the hand.

Conclusion: In this observational study, we have provided a detailed analysis of hand and wrist urate distribution in gout.
\end{abstract}

Key Words: Gout; Hand; Tomography, X-ray computed; Uric acid

Correspondence: Dr Y Leng, Department of Radiology, Tuen Mun Hospital, Hong Kong

Email:ly108@ha.org.hk

Submitted: 27 Nov 2019; Accepted: 21 Jan 2020

Contributors: All authors designed the study. YL, AOCL, SKC and KYC acquired the data. YL analysed the data and drafted the manuscript. All authors critically revised the manuscript for important intellectual content. All authors had full access to the data, contributed to the study, approved the final version for publication, and take responsibility for its accuracy and integrity.

Conflicts of Interest: All authors have disclosed no conflicts of interest.

Funding/Support: This research received no specific grant from any funding agency in the public, commercial, or not-for-profit sectors.

Ethics Approval: The study was approved by the New Territories West Cluster Clinical Ethics Committee (Ref NTWC/REC/19082). 


\title{
中文摘要
}

\section{慢性痛風患者手腕尿酸鈵結晶的分佈}

\author{
冷泳美、周朗妍、徐碩君、葉篠笏、陳煥章、蔡啟堯、李安慈
}

\author{
目的 : 透過隻能電腦斷層掃描 $(\mathrm{DECT})$ 檢查非急性痛風患者手腕中尿酸鈵 $(\mathrm{MSU})$ 結晶沉積發生 \\ 率和分佈模式。
}

方法 : 收集2015年3月至2019年3月期間, 慢性痛風石患者於結晶溶出治療前接受檢查的所有手腕 DECT影像。排除沒有陽性MSU結晶沉積的病例。回顧分析陽性病例的報告和影像, 並記錄所有 MSU結晶沉積的解剖位置。

\begin{abstract}
結果：陽性結果共48例, 單手及雙手DECT分別佔 30 例及 18 例。共 60 隻手或手腕有屈肌腱受累。 腕關節是最常受累的部位 $(78.2 \%)$ 。腕管是手部及腕部最常見的受累軟組織部位 $(71.8 \%)$ ，其 次是第四側伸肌腔 $(55.1 \%)$ 和第五側伸肌腔 $(53.8 \%)$ 。食指伸肌是手部最常受累的軟組織部位 ( $47.4 \%)$, 而無名指屈指肌是手部最常受累的屈肌腱部位 $(46.2 \%)$ 。在手和手腕軟組織部位, 拇 短伸肌 $(11.5 \%)$ 、尺側腕屈肌 $(11.5 \%)$ 和伸肌隔腔第1區 $(11.5 \%)$ 最不常見。手部屈肌腱受累的 最常見區域包括第2區 $(75 \%)$ 和第4區 $(78.3 \%)$ 。
\end{abstract}

結論 : 這項觀察性研究為痛風患者手腕MSU分佈提供了詳細分析。

\section{INTRODUCTION}

Gout is a disease associated with deposition of monosodium urate (MSU) crystals. Acute gouty arthritis is characterised by the rapid onset of severe pain, swelling, warmth, erythema, and decreased range of motion in the affected joint. ${ }^{1}$ Chronic tophaceous gout is associated with progressive joint damage, chronic pain, and disability.

The diagnosis of gout has been based on clinical presentation, laboratory results, joint aspiration, and imaging. Patients typically present with mono-articular arthritis, often affecting the first metatarsophalangeal (MTP) joint. ${ }^{2}$ Hyperuricaemia is an inconsistent finding. Patients may have 'normal' serum urate levels during an acute gout attack. Some patients may have 'asymptomatic hyperuricaemia' without clinical manifestations of gout or urate crystal deposition. ${ }^{3}$ The gold standard for diagnosis of gout is presence of birefringent MSU crystals from the joint aspirate. However, joint aspiration is a painful invasive procedure and may be false-negative for MSU crystals even when acute gouty arthritis is present.

Various imaging modalities have been used for the diagnosis of gout, such as radiography, ultrasound, computed tomography (CT), and magnetic resonance imaging (MRI). On plain X-ray, 'punched-out' erosions with overhanging edges are a typical manifestation of chronic gout. Ultrasound features of gout include joint effusion, synovitis, erosions, tophi, crystalline aggregates and the 'double contour sign' which is existence of a hyperechoic band over anechoic cartilage. ${ }^{4}$ MRI features of gouty arthropathy are variable and nonspecific including tophi with variable intensity on T1-weighted or T2-weighted sequences and variable enhancement pattern. ${ }^{5}$ These imaging modalities are not highly sensitive or specific for identifying MSU crystals.

Dual-energy CT (DECT) is advanced technology that enables excellent visualisation of soft tissue structures, such as tendons, ligaments, and bursae. It has been used for the non-invasive diagnosis of established gout with high sensitivity and specificity. ${ }^{6}$ DECT depends on an accumulation of MSU crystals and is not particularly accurate for determining acute, early gout. DECT is particularly helpful in accurate quantification of MSU deposits and for follow-up. The hand and wrist are common sites of gouty crystal deposition. However, MSU involvement of bone/joint and soft tissue in the hands and wrists has not been systematically characterised.

The aim of this study was to examine the frequency and patterns of bone/joint and soft tissue involvement in the hand and wrist of patients with gout using DECT. We hope to improve understanding of the pathogenesis, prompt diagnosis, and management of gout with more detailed knowledge of urate deposition in this disease. 


\section{METHODS}

This was a retrospective, observational study. In our hospital, patients with chronic tophaceous gout are referred for DECT from the Department of Orthopaedics for pretreatment assessment. Referred patients undergoing their first DECT of the hand and wrist between March 2015 and March 2019 were identified via the electronic health records system. Cases with positive MSU crystal deposition in the hand and wrist were included.

Scans were performed using our dual-source DECT scanner (Siemens SOMATOM Definition Flash). Parameters were $140 \mathrm{kV}$ for one tube and $80 \mathrm{kV}$ for the other. A two-material decomposition algorithm was performed on a multi-technique CT workspace. The material-specific difference in attenuation of urate between the two energy levels at $80 \mathrm{kV}$ and $140 \mathrm{kV}$

Table 1. Urate distribution by anatomical structure in the wrist.

\begin{tabular}{lc}
\hline Site & Affected cases $(\mathrm{n}=78)^{\star}$ \\
\hline Radiocarpal joint & $36(46.2 \%)$ \\
Ulnocarpal joints & $38(48.7 \%)$ \\
Carpal joints & $61(78.2 \%)$ \\
Palmar side & \\
Carpal tunnel & $56(71.8 \%)$ \\
Flexor carpi ulnaris & $9(11.5 \%)$ \\
Flexor carpi radialis & $35(44.9 \%)$ \\
Dorsal side & \\
Extensor compartment I & $9(11.5 \%)$ \\
Extensor compartment II & $14(17.9 \%)$ \\
Extensor compartment III & $12(15.4 \%)$ \\
Extensor compartment IV & $43(55.1 \%)$ \\
Extensor compartment V & $42(53.8 \%)$ \\
Extensor compartment VI & $29(37.2 \%)$ \\
\hline
\end{tabular}

* Data are presented as No. (\%).

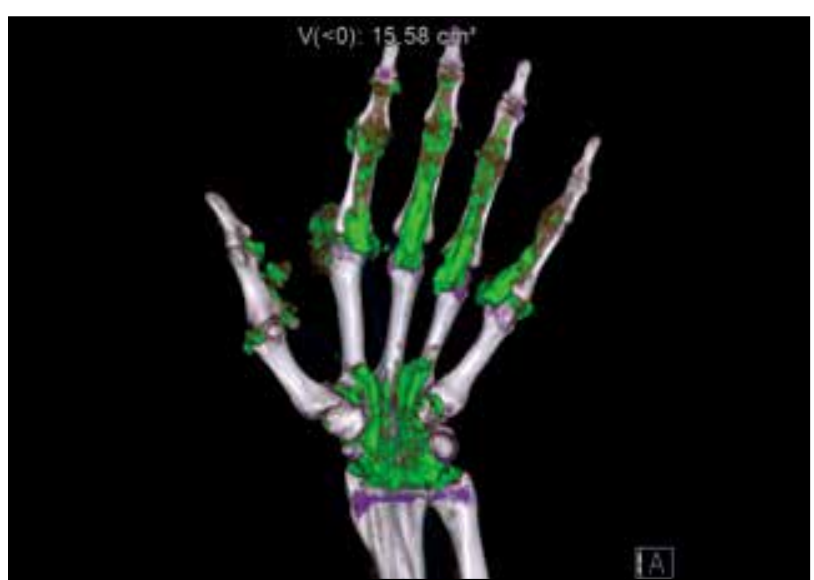

Figure 1. Dual-energy computed tomography image showing involvement of tendons, soft tissue and joints in a patient with tophaceous gout. Three-dimensional volume-rendered image demonstrating monosodium urate crystal deposition in the flexor digitorum I-V tendons and the carpal tunnel. allowed accurate detection of MSU, which was then colour coded as green and fused onto the standard greyscale CT image. These were reviewed as both crosssectional and three-dimensional images.

We analysed the reports and images of the positive cases, with locations of all urate deposition recorded and classified by anatomical location. MSU crystal deposition in DECT scans were scored at the tendon sites, joints, carpal tunnel, and flexor tendon anatomic zones according to the classification of Kleinert et $\mathrm{al}^{7}$ and Verdan. ${ }^{8}$ Zone V (from the musculotendinous junction to the proximal aspect of the carpal tunnel) was not included in the analysis because it was not completely included in the scan range in some of the cases.

\section{RESULTS}

Among 73 referred patients undergoing first DECT of the hand and wrist during the study period, 48 patients were identified with positive findings who met the inclusion criteria. Patients with positive findings consisted of 47 men and one woman with median age 61 years (range, 31-89 years). Among them, 30 patients underwent DECT of both hands and 18 patients underwent DECT of a single hand. Therefore, a total of 78 wrists and hands were affected.

As shown in Table 1, the carpal tunnel was the most commonly involved soft tissue site at the wrist (71.8\%) [Figure 1], followed by the fourth $(55.1 \%)$ and fifth (53.8\%) extensor compartments (Figure 2). In the

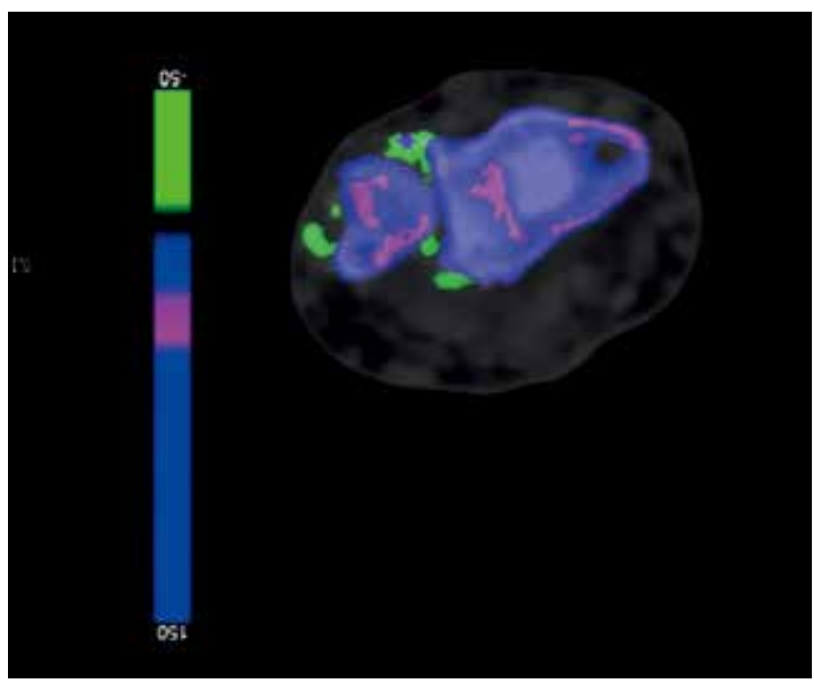

Figure 2. Dual-energy computed tomography image showing involvement of tendons and soft tissue in a patient with tophaceous gout. Two-dimensional axial image shows monosodium urate crystal deposition (green) at extensor compartment V-VI and distal radioulnar joint. 
hands, the second digit extensor digitorum tendon was the most commonly (47.4\%) involved soft tissue site in the hand, while the fourth digit flexor digitorum was the most commonly $(46.2 \%)$ involved flexor tendon in the hand (Table 2). The intercarpal joints were the most commonly involved site $(78.2 \%)$. A total of 60 (77\%) of the 78 hands/wrists studied had flexor tendon involvement. Zones II (75\%) and IV (78.3\%) were the most commonly involved flexor tendon zones (Table 3 ).

\section{DISCUSSION}

The reported prevalence of gout in Hong Kong has risen continuously over the past decade. In 2016, the crude prevalence of gout in Hong Kong was $2.9 \%$, which is similar to rates reported in Western countries.?

A few studies about the distribution of gout have shown that the lower extremity is more often affected than the upper extremity. ${ }^{10-12}$ Gout in the first MTP joint is accepted as the most common site of involvement in clinical and radiographic studies. ${ }^{13,14}$ A DECT study of 148 newly diagnosed gout patients showed the first MTP

Table 2. Urate distribution by anatomical structure in the hand.

\begin{tabular}{lc}
\hline Site & Affected cases $(\mathrm{n}=78)^{\star}$ \\
\hline First metacarpophalangeal joint & $26(33.3 \%)$ \\
Other metacarpophalangeal joints & $58(74.4 \%)$ \\
(second to fifth) & \\
Interphalangeal joints & $46(59.0 \%)$ \\
Palmar side & $29(37.2 \%)$ \\
$\quad$ Flexor digitorum I & $23(29.5 \%)$ \\
$\quad$ Flexor digitorum II & $21(26.9 \%)$ \\
$\quad$ Flexor digitorum III & $36(46.2 \%)$ \\
$\quad$ Flexor digitorum IV & $36(46.2 \%)$ \\
$\quad$ Flexor digitorum V & \\
Dorsal side & $9(11.5 \%)$ \\
$\quad$ Extensor pollicis brevis & $10(12.8 \%)$ \\
$\quad$ Extensor pollicis longus & $37(47.4 \%)$ \\
$\quad$ Extensor digitorum II & $36(46.2 \%)$ \\
$\quad$ Extensor digitorum III & $14(17.9 \%)$ \\
Extensor digitorum IV & $20(25.6 \%)$ \\
$\quad$ Extensor digitorum V &
\end{tabular}

* Data are presented as No. (\%).

Table 3. Urate distribution in different flexor tendon anatomic zones.

\begin{tabular}{lc}
\hline Zone & Affected cases $(\mathrm{n}=60)^{\star}$ \\
\hline $\mathrm{I}$ & $28(46.7 \%)$ \\
II & $45(75.0 \%)$ \\
III & $35(58.3 \%)$ \\
IV & $47(78.3 \%)$ \\
TI & $16(26.7 \%)$ \\
TII & $18(30.0 \%)$ \\
TIII & $4(6.7 \%)$ \\
\hline
\end{tabular}

* Data are presented as No. (\%). joint to be the most common site of urate deposition (44.6\%) and much more common than other MTP joints $(17.6 \%)$. We found that gout affecting the first MCP joint is less common than the other MCP joints.

Our study shows that MSU crystal deposition in the hand and wrist is most common in the carpal joints $(78.2 \%)$, followed by the MCP joints (75.6\%), and interphalangeal joints $(59 \%)$. This is comparable to previous studies. Research done by Mallinson et $\mathrm{al}^{10}$ reviewing 148 DECT cases for the distribution of urate deposition showed that carpus $(12.5 \%)$ also had higher urate deposition than interphalangeal joints (6.4\%) and MCP joints (7.4\%). Our study has a much higher prevalence of positive findings than Mallinson et al, ${ }^{10}$ which included DECT images of hands/wrists, feet/ankles, elbows, and knees, whereas our study focused only on the hands and wrists. Another study on DECT of 97 patients with gout also showed that the carpal joints $(56.7 \%)$ had a higher rate of urate deposition than the metacarpophalangeal joints $(42.3 \%) .{ }^{15}$

Our results show that MSU crystal deposition in the tendons of the hands/wrists is very common in patients with gout. A previous DECT study of tendon involvement in the feet of 92 patients with gout also found common tendon/ligament involvement in about $65 \%$ of feet. ${ }^{16}$ The exact mechanism on why there is crystal deposition on tendons is not known. Biomechanical strain as a result of the pressure burden on these tendons may contribute to crystal deposition. ${ }^{17}$ Spontaneous rupture of tendons secondary to gouty tophaceous deposits can occur. ${ }^{18,19}$ MSU crystal deposition in hands/wrists can affect function. In a study of 20 patients with gout, tophaceous joint disease strongly predicted impaired hand function. ${ }^{20}$ The number of joints in the hand with tophi was the strongest single predictor of the Sollerman score, and also predicted other measures of hand mobility and function. Kleinert et $\mathrm{al}^{7}$ and Verdan ${ }^{8}$ have classified tendon injuries into five anatomic zones which can have impact on flexor tendon injury treatment and prognosis. Our study analysed MSU crystal deposition in four of the five different flexor tendon anatomic zones. We found zones II (75\%) and IV (78.3\%) were the most commonly involved flexor tendon zones in the hand.

We found that $48.7 \%$ of the cases had MSU crystal deposition in the ulnocarpal joints. Another DECT study of 97 patients with gout showed $54.6 \%$ of patients had urate deposition in the triangular fibrocartilage complex/ distal radioulnar joint. ${ }^{19}$ This is similar to our study. A 
study on arthroscopic findings of seven patients with wrist gout found focal crystalline precipitates on the scapholunate and lunotriquetral ligaments but not on the triangular fibrocartilage complex..$^{21}$

We found that the carpal tunnel was the most commonly involved soft tissue site in the hand and wrist (71.8\%). Urate deposition in the carpal tunnel can cause secondary carpal tunnel syndrome..$^{22,23}$

DECT has relatively high sensitivity and specificity for the diagnosis of gout. Sensitivity and specificity for DECT was $100 \%$ and $79 \%$ to $89 \%$, respectively in a study of 31 patients who underwent both DECT and joint aspiration. ${ }^{24} \mathrm{~A}$ meta-analysis of seven studies found DECT to have a sensitivity of $88 \%$ and specificity of $90 \%$ for gout. ${ }^{25}$

Our study has some limitations. It was retrospective with a small number of cases and all DECT examinations were evaluated by a single radiologist. Patients were recruited from orthopaedic clinics, where their gout may have been partially treated. All included patients had chronic tophaceous gout, which is usually associated with a number of co-morbidities, including hypertension, cardiovascular disease, renal impairment, diabetes, obesity, and hyperlipidaemia. So, this may contribute to selection bias. Smaller concentrations of MSU may not be accurately seen on DECT ${ }^{26}$ so it is possible that small MSU crystal deposits may not have been detected his method. False-negative results can also occur in tophi with lower crystal concentrations. In short, the population of the study is heterogeneous and small. Further multicentre studies with more patients would be helpful to confirm our findings.

\section{CONCLUSION}

In this study, we have provided a detailed analysis of hand and wrist urate distribution in gout. Our study supports that gout affects different locations within the soft tissue and joints with predilection for particular areas.

\section{REFERENCES}

1. Neogi T. Clinical practice. Gout. N Engl J Med. 2011;364:443-52.

2. Roddy E. Revisiting the pathogenesis of podagra: why does gout target the foot? J Foot Ankle Res. 2011;4:13.

3. Roddy E, Doherty M. Epidemiology of gout. Arthritis Res Ther. 2010;12:223.

4. Thiele RG, Schlesinger N. Diagnosis of gout by ultrasound, Rheumatology (Oxford). 2007;46:1116-21.

5. Girish G, Glazebrook KN, Jacobson JA. Advanced imaging in gout. AJR Am J Roentgenol. 2013;201:515-25.

6. Nicolaou S, Yong-Hing CJ, Galea-Soler S, Hou DJ, Louis L,
Munk P. Dual-energy CT as a potential new diagnostic tool in the management of gout in the acute setting. AJR Am J Roentgenol. 2010;194:1072-8.

7. Kleinert H, Kutz J, Ashbell TS, Martinez E. Primary repair of lacerated flexor tendons in "no man's land". J Bone Joint Surg. 1967;49A:577.

8. Verdan CE. Half a century of flexor-tendon surgery. Current status and changing philosophies. J Bone Joint Surg Am. 1972;54:472-91.

9. Centre for Health Protection, Department of Health, Hong Kong SAR Government. Gout: No longer the disease of kings. Available from:https://www.chp.gov.hk/files/pdf/ncd_watch_april_2019.pdf. Accessed 12 Nov 2020.

10. Mallinson PI, Reagan AC, Coupal T, Munk PL, Ouellette H, Nicolaou S. The distribution of urate deposition within the extremities in gout: a review of 148 dual-energy CT cases. Skeletal Radiol. 2014;43:277-81.

11. Dhanda S, Jagmohan P, Quek ST. A re-look at an old disease: a multimodality review on gout. Clin Radiol. 2011;66:984-92.

12. Roddy E, Zhang W, Doherty M. Are joints affected by gout also affected by osteoarthritis? Ann Rheum Dis. 2007;66:1374-7.

13. Monu JU,Pope TL Jr. Gout: a clinical and radiologic review. Radiol Clin North Am. 2004;42:169-84.

14. Stewart S, Dalbeth N, Vandal AC, Rome K. The first metatarsophalangeal joint in gout: a systematic review and metaanalysis. BMC Musculoskeletal Disord. 2016;17:69.

15. Klauser AS, Halpern EJ, Strobl S, Abd Ellah MM, Gruber J, Bellmann-Weiler R, et al. Gout of hand and wrist: the value of US as compared with DECT. Eur Radiol. 2018;28:4174-81.

16. Dalbeth N, Kalluru R, Aati O, Horne A, Doyle AJ, McQueen FM. Tendon involvement in the feet of patients with gout: a dual-energy CT study. Ann Rheum Dis. 2013;72:1545-8.

17. Sun Y, Ma L, Zhou Y, Chen H, Ding Y, Zhou J, et al. Features of urate deposition in patients with gouty arthritis of the foot using dualenergy computed tomography. Int J Rheum Dis. 2015;18:560-7.

18. Mahoney PG, James PD, Howell CJ, Swannell AJ. Spontaneous rupture of the Achilles tendon in a patient with gout. Ann Rheum Dis. 1981;40:416-8.

19. Jerome JT, Varghese M, Sankaran B, Thomas S, Thirumagal SK Tibialis anterior tendon rupture in gout - Case report and literature review. Foot Ankle Surg. 2008;14:166-9.

20. Dalbeth N, Collis J, Gregory K, Clark B, Robinson E, McQueen FM. Tophaceous joint disease strongly predicts hand function in patients with gout. Rheumatology (Oxford). 2007;46:1804-7.

21. Wilczynski MC, Gelberman RH, Adams A, Goldfarb CA. Arthroscopic findings in gout of the wrist. J Hand Surg Am. 2009;34:244-50.

22. Ge Y, Li F, Chen J, Tian J. Severe carpal tunnel syndrome caused by gouty tophi diagnosed by dual energy computed tomography: case report. Arch Rheumatol. 2016;31:284-6.

23. $\mathrm{Lu} \mathrm{H}$, Chen Q, Shen H. A repeated carpal tunnel syndrome due to tophaceous gout in flexor tendon: a case report. Medicine (Baltimore). 2017;96:e6245.

24. Glazebrook KN, Guimarães LS, Murthy NS, Black DF, Bongartz T, Manek NJ, et al. Identification of intraarticular and periarticular uric acid crystals with dual-energy CT: initial evaluation. Radiology. 2011;261:516-24.

25. Yu Z, Mao T, Xu Y,Li T, Wang Y, Gao F, et al. Diagnostic accuracy of dual-energy CT in gout: a systematic review and meta-analysis. Skeletal Radiol. 2018;47:1587-93.

26. Primak AN, Fletcher JG, Vrtiska TJ, Dzyubak OP, Lieske JC, Jackson ME, et al. Noninvasive differentiation of uric acid versus non-uric acid kidney stones using dual-energy CT. Acad Radiol. 2007;14:1441-7. 